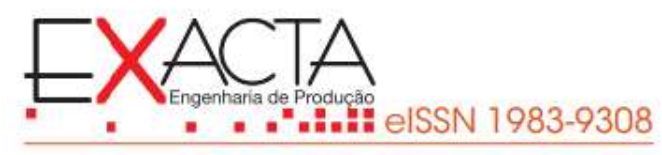

\title{
Eficiência da produção leiteira na microrregião de Dourados/MS: aplicação da análise envoltória de dados
}

\author{
Efficiency of dairy production in Dourados/MS microregion: application of data \\ envelopment analysis
}

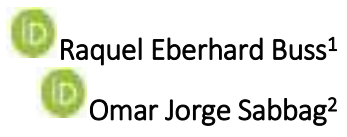

Fábio Henrique Paniagua Mendieta ${ }^{3}$
${ }^{1}$ Universidade Estadual de Mato Grosso do Sul UEMS - campus de Ponta Porã/MS, Brasil. Mestre em Desenvolvimento Regional e Sistemas

Produtivos.

raquelbuss89@hotmail.com

2Universidade Estadual Paulista "Júlio de Mesquita Filho" - campus de Ilha Solteira/SP, Brasil. Pós-doutor e livre docente (área Economia e Gestão do Agronegócio). omar.sabbag@unesp.br

${ }^{3}$ Docente do Instituto Federal de Mato Grosso do Sul - IFMS campus de Ponta Porã/MS, Brasil. Mestre em Integração Latino Americana pela Universidade Federal de Santa Maria/RS. fabio.mendieta@ifms.edu.br

\begin{abstract}
Resumo
A cadeia produtiva de leite no Brasil é de suma importância; entretanto, encontrar a melhor forma de utilizar os insumos disponíveis torna-se um desafio para os produtores. Destaca-se que a análise envoltória de dados (Data Envelopment Analysis - DEA) tem sido extensivamente utilizada como apoio à gestão, na estimativa do desempenho relativo de unidades produtivas semelhantes entre si. Objetivou-se avaliar a eficiência técnica de 15 propriedades produtoras de leite pertencentes a Microrregião de Dourados/ MS, por meio do método DEA. No modelo variável de escala, $20 \%$ das DMU's apresentaram eficiência e $80 \%$ ineficientes, apresentando retornos crescentes a escala. No modelo Tobit, as variáveis mais expressivas foram assistência técnica, melhoramento genético e complementação alimentar. Conclui-se que esta ferramenta serve como suporte aos produtores que tenham interesse de investir e potencializar os resultados da atividade leiteira, que além de gerar ganhos comerciais, também cumpre com o papel social.
\end{abstract}

Palavras-chave: Análise DEA. Desempenho. Gestão. Leite.

\section{Abstract}

The milk production chain in Brazil is extremely important; however, find the best way to use the available inputs it becomes a challenge for producers. It should be noted that Data Envelopment Analysis (DEA) has been extensively used to support management in estimating the relative performance of similar productive units among themselves. It was aimed to evaluate the technical efficiency of 15 milk producing properties belonging to the microregion of Dourados, Mato Grosso do Sul state, by means of the DEA method. In the variable scale model, $20 \%$ of the DMU's presented efficiency and $80 \%$ inefficiencies, presenting increasing returns to scale. In the Tobit model, the most significant variables were technical assistance, genetic improvement and food supplementation. It is concluded that this tool serves as a support to producers who have an interest in investing and boost the results of the dairy activity, which in addition to generating commercial gains, also fulfills the social role.

Keywords: DEA analysis. Performance. Management. Milk. 
1 Introdução

O leite é um produto alimentício muito importante para a dieta humana, pois ele e seus derivados são os principais alimentos constituintes de cálcio para o organismo, que com alto grau de absorção favorece a manutenção do sistema ósseo, circulatório e no fluido extracelular, além de possuir vários nutrientes, reforçando a sua importância para o consumo (Sban, 2015).

A produção do leite é o ponto inicial para mover uma cadeia produtiva envolvendo vários setores e operações; especificamente a cadeia agroindustrial do leite no Brasil, podendo ser representada por sete segmentos principais, dentre eles a produção primária de leite (Gomes e Leite, 2001).

Em termos de produção de leite, a produção brasileira de leite cresceu 271\% entre 1974 e 2017, enquanto a média mundial ficou em 75\%. Isso fez o Brasil saltar de 10 para 3o país maior produtor do mundo no período, ficando apenas atrás dos Estados Unidos e da Índia (Anuário do Leite, 2019).

A atividade leiteira também exerce um papel social. Muitos estabelecimentos produzem o leite apenas para autoconsumo, porém, a grande maioria (55\%) produz excedentes, proporcionando a opção de comercialização e assim o complemento da renda (Zoccal, 2012), fazendo-a responsável por elevada absorção de mão de obra rural (contratada e familiar), propiciando a fixação do homem no campo, principalmente para agricultura familiar, responsável por $58 \%$ do leite produzido no Brasil (BNDES, 2013).

Por outro lado, a pecuária leiteira ainda enfrenta grandes desafios como a baixa escala de produção, o distanciamento dos padrões técnicos recomendados, configurando uma atividade em desenvolvimento, com alto potencial a ser trabalhado, possibilitando melhor resultado em produtividade, qualidade, escala de produção e consequentemente expansão de níveis econômicos e sociais, a partir de incorporação de técnicas voltadas a atividade e utilização dos insumos de maneira mais eficiente. Perante tal realidade, surge a seguinte indagação: "Os produtores de leite pertencentes à microrregião de Dourados estão sendo eficientes na produção de leite? Quais são os fatores que levam à eficiência ou ineficiência desses produtores?"

Entende-se por eficiência a comparação entre valores observados e valores ótimos de insumos e produtos, relacionando-se o que foi produzido com recursos disponíveis, com o que poderia ter sido produzido com os mesmos recursos (Tupy \& Yamaguchi, 1998).

Neste sentido, a Análise Envoltória de Dados (ou data envelopment analysis - DEA) é uma técnica não paramétrica de medição de eficiência relativa, que ao se estimar a função fronteira a partir da utilização dos insumos, se obterá a eficiência das unidades tomadoras de decisão (DMU's - 
decision making units ${ }^{1}$, ou UTD). É preciso identificar quais as variáveis e ferramentas serão utilizadas, tendo esses itens como parâmetros na busca pela identificação do grau de eficiência de cada DMU.

Neste contexto, objetivou-se mensurar o desempenho global em 15 propriedades produtoras de leite na Microrregião (MRG) de Dourados/MS por meio da técnica DEA. Especificamente pretendeu-se: i) caracterizar as DMU's selecionadas; ii) avaliar a Eficiência Global; iii) identificar as propriedades eficientes, bem como apontar o diferencial de cada insumo para alcançar a eficiência na produção leiteira; iv) avaliar a ineficiência de escala; e v) identificar as principais variáveis que influenciam a eficiência, aplicando o modelo Tobit.

\section{Referencial Teórico}

\subsection{Eficiência aplicada à produção leiteira}

Além de participar na formação da renda de grande número de produtores, a produção de leite no país também é responsável por elevada absorção de mão de obra rural (contratada e familiar), propiciando a fixação do homem no campo (Campos \& Piacenti, 2007).

Segundo Fiore e Araújo (2002), no Brasil cerca de 7,4 milhões de trabalhadores agrícolas, ou seja, $10 \%$ da população economicamente ativa do país não são remunerados ou produzem apenas para a sobrevivência, vivendo em condições precárias, com baixa escolaridade e oportunidades de ingresso no mercado de trabalho limitadas.

Entretanto, a pecuária leiteira brasileira ainda vem enfrentando dificuldades atribuídas ao baixo nível tecnológico de pequenos produtores que são a grande maioria (Mondaini, 1996). A modernização da atividade produtiva com a intensificação dos sistemas de produção e a adoção de novas tecnologias podem contribuir para aumentar a disponibilidade de leite para a população, a menores custos (Matos, 1996), que inferem na melhor eficiência do sistema produtivo.

Essas observações merecem destaque, considerando que: i) representam a maioria dos estabelecimentos produtores de leite; ii) não se deve apreciar apenas o fator econômico gerado nesse caso; ii) esses estabelecimentos estão inseridos num contexto muito maior e complexo, que compreende a questão social em que estão envolvidos: promovem a distribuição de renda, são grandes responsáveis pela absorção de mão de obra rural (contratada e familiar), propiciam a fixação do homem no campo, assegurando a manutenção da agropecuária e consequentemente do agronegócio.

Para medir a eficiência de uma empresa a partir dos insumos, busca-se estimar a função fronteira. Essa função é o padrão em relação ao qual será medida a eficiência das firmas observadas. A

\footnotetext{
${ }^{1}$ Define-se como DMU (Decision Making Units), uma firma, departamento, propriedade rural ou unidade administrativa cuja eficiência está sendo analisada. O conjunto de DMU's utilizadas em uma DEA deve ter em comum a utilização dos mesmos insumos e produtos e, também, tem que ser homogêneas e terem autonomia na tomada de decisões (LINS; MEZA, 2000). Pode ser usado também como mesma referência a sigla UTD - unidades tomadoras de decisão, porém nesse trabalho optou-se por DMU, termo este utilizado na maioria dos trabalhos acadêmicos.
} 
função de produção de fronteira mostrará o máximo de produto possível de obter a partir de um nível de insumos. Da mesma forma, a função de custo fronteira mostrará o mínimo de custo possível para produzir um nível de produto, dados os preços de insumos (Tupy \& Yamaguchi, 1998). No caso dessa análise, os desvios dessa fronteira serão interpretados como ineficiência.

A Análise Envoltória de Dados (DEA), técnica não paramétrica de medição de eficiência relativa, vem sendo utilizada com maior frequência no Brasil desde 1997, nos diferentes setores da economia do país (Kassai, 2002).

Em um estudo feito por Carmo (2012), utilizou o DEA para medir a eficiência e produtividade aplicados à agricultura familiar, demonstrando que esse método mostrou-se bastante adequado para diversos setores da economia, não sendo diferente para a agricultura familiar. Segundo o autor, ao aplicar a DEA identificaram-se as principais fontes de ineficiência e as metodologias aplicadas pelas unidades produtivas eficientes que servem de referência para os demais produtores.

Em relação a eficiência de propriedade leiteiras, a análise DEA já foi aplicada em algumas pesquisas, como a de Santos et al. (2005), que observaram que dentre os 17 produtores de leite em Viçosa/MG, uma porção significativa de propriedades ineficientes tecnicamente. Também a pesquisa feita por Rodrigues et al. (2010), em Rolim de Moura/RO, buscou avaliar a eficiência relativa a partir da DEA em pequenas propriedades produtoras de leite, classificando-as como eficientes ou ineficientes, explicitando os fatores explicativos dessa eficiência, caso em que a maioria dos produtores se apresentaram ineficientes tecnicamente.

\section{Material e Métodos}

\subsection{Caracterização da região de estudo}

A pesquisa foi realizada na MRG de Dourados, Estado de Mato Grosso do Sul, composta por 15 municípios, sendo eles: Amambai, Antônio João, Aral Moreira, Caarapó, Douradina, Dourados, Fátima do Sul, Itaporã, Juti, Laguna Caarapã, Maracaju, Nova Alvorada do Sul, Ponta Porã, Rio Brilhante e Vicentina (Brasil, 2015).

Segundo Barbosa (2013), o desempenho do agronegócio é o segundo principal fator determinante que impacta sobre o processo de desenvolvimento dos municípios da MRG, principalmente nos municípios de Maracaju, Rio Brilhante e Ponta Porã. O Estado possui cerca de 70 unidades industriais, entre laticínios e usinas de beneficiamento, que operam sob inspeção federal e estadual, processando cerca de 190 milhões de litros de leite/ano (Brasil, 2015).

\subsection{Descrição do método}

A pesquisa foi desenvolvida utilizando a "Análise Envoltória de Dados" (DEA), pois é uma ferramenta analítica e quantitativa que permite medir e avaliar a eficiência. Segundo Rodrigues (2010, 
p. 40) a técnica DEA "foi desenvolvida inicialmente por Charnes, Cooper e Rhodes (1978), com o objetivo de determinar a eficiência econômica relativa das empresas, excluindo o aspecto financeiro, e trabalhando com múltiplos insumos e produtos". Essa ferramenta pode ser conceituada como uma técnica de pesquisa operacional de unidades de produção.

Essa ferramenta traz a caracterização de uma medida de eficiência, fazendo com que a decisão fique orientada por um único indicador, construído a partir de várias abordagens de desempenho diferentes, facilitando o processo decisório, em que o gestor utiliza apenas a medida de eficiência DEA para concluir a respeito do desempenho da empresa ou unidade de análise.

Para medir a eficiência de uma DMU pelos insumos, busca-se estimar a função fronteira, que é o padrão em relação ao qual será medida a eficiência das firmas observadas. A função de produção de fronteira mostrará o máximo de produto possível de obter a partir de um nível de insumos, sendo os desvios serão entendidos como ineficiência (Tupy \& Yamaguchi, 1998).

O número de amostragem foi representado por DMU's (cada município da MRG teve uma propriedade analisada). Segundo Ali e Seiford (1993), para que a análise apresente resultados satisfatórios, é necessário que o número de unidades seja, ao mínimo, duas vezes o número de insumos $(x)$ e produtos $(y)$. Logo, o número de unidades necessárias $>2(x+y)$. Como foram analisadas 15 unidades de produção (DMU's 1 a 15), com $x=4$ e $y=1$, atende-se de forma satisfatória para a validação da técnica.

As variáveis utilizadas serviram para elaboração das matrizes de dados, sendo uma matriz de insumo e outra de produtos. Segundo Rodrigues (2010, p. 65) "a matriz X de insumos, de ordem (k X $n)$, é composta por insumos, utilizados por $n$ produtores. Já a matriz $Y$ de produtos, ordem $(m \times n)$ é composta por $\mathrm{m}$ produtos, produzidos pelos $\mathrm{n}$ produtores". As variáveis de estudo estão representadas por $\mathrm{Y} 1, \mathrm{X} 1, \mathrm{X} 2, \mathrm{X} 3$ e $\mathrm{X} 4$, conforme Quadro 1. Variáveis semelhantes também foram utilizadas por Rodrigues (2010).

As variáveis do estudo foram: Y1-Produção mensal de leite, em litros. (output 1); X1- Mão de obra (no de pessoas). (input 1); X2- Área destinada as vacas em lactação, medidas em hectares, obtida somando-se as áreas com pastagens (natural e formada, cana de açúcar, capineira e silagem). (input 2); X3- Quantidade de vacas em lactação. (input 3) e X4-Capital investido em benfeitorias máquinas e equipamentos (R\$). (input 4).

Segundo Alves (1999), a matriz X deve apresentar níveis de uso de insumos não-negativos e cada linha e coluna deve conter pelo menos um nível de insumo positivo, ou seja, cada DMU consome ao menos um insumo, e uma DMU, pelo menos, consome o insumo que está em cada linha, seguindo a fórmula (I), conforme Quadro 1. Enquanto a matriz Y apresenta níveis de produção não-negativos, cada produto é produzido por uma DMU, pelo menos, e cada DMU produz pelo menos um produto, expresso pela fórmula (II) conforme quadro 1. 
Após a organização das matrizes, aplicou-se o modelo em todos os produtores, buscando encontrar a redução proporcional no uso de insumos pelos produtores, sem alterar a quantidade produzida, conforme expressão (III) expressa no Quadro 1.

Para cada medida de eficiência encontrada pela fórmula acima, tem-se u que é um vetor ( $\mathrm{m} x$ 1) de pesos nos produtos e vé um vetor de pesos nos insumos. Para selecionar os pesos ótimos para cada DMU especifica-se um problema de programação matemática (Tupy e Yamaguchi, 2002). Para a i-ésima DMU, tem-se (IV) descrita no Quadro 1. O modelo pode ser linearizado, tornando possível sua solução por meio de métodos de programação linear convencionais, conforme (V), no Quadro 1. Pela dualidade em programação linear, pode-se chegar a um modelo dual da formulação linearizada. Se for igual a um, a DMU será eficiente; caso contrário, é ineficiente (Carmo, 2012), conforme (VI).

Quadro 1 - Variáveis de estudo e formulações matemáticas do modelo DEA

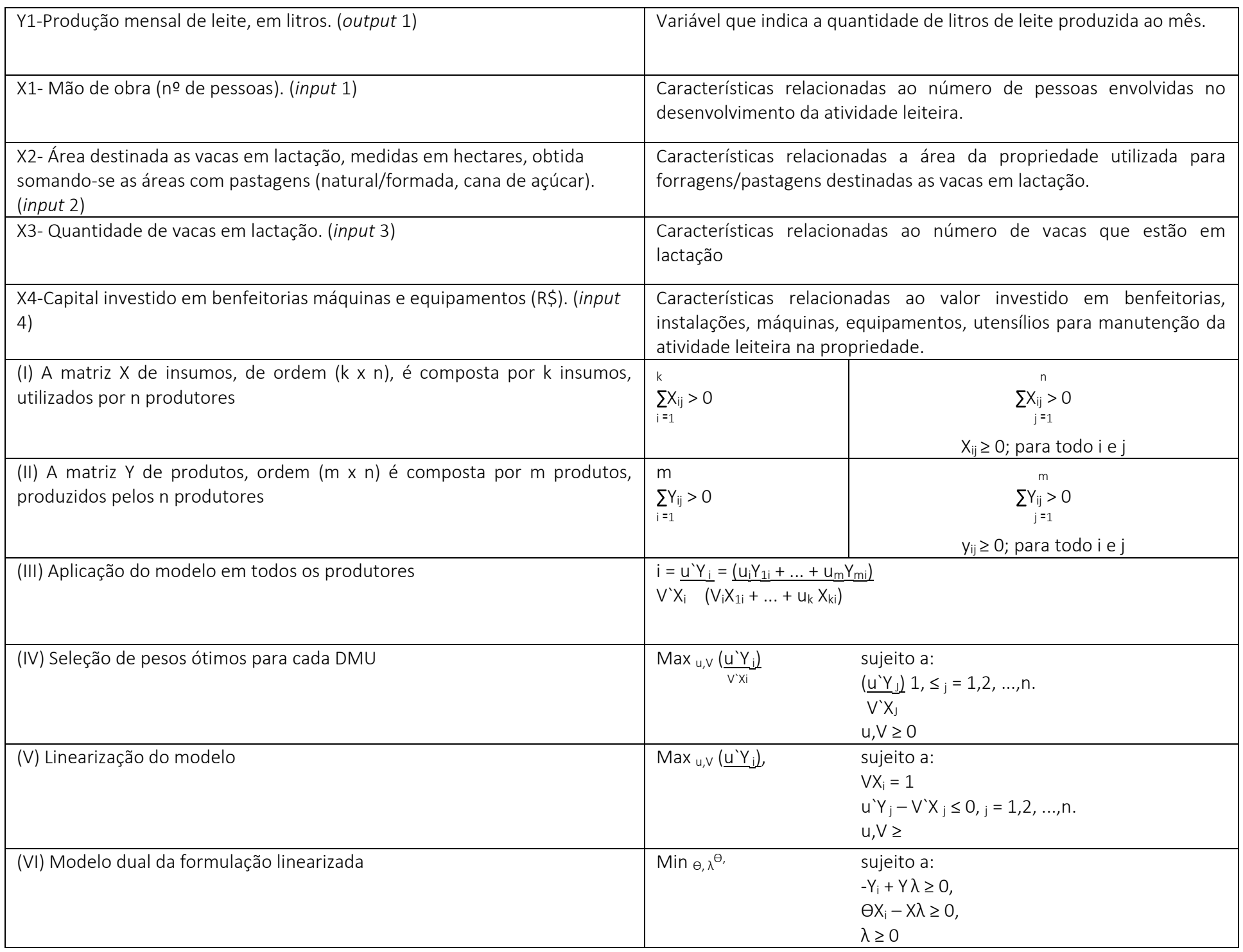

Fonte: Elaborado pela autora com base em Rodrigues (2010), Alves (1999), Tupy e Yamaguchi (2002) e Carmo (2012).

A ferramenta DEA fornece um indicador de eficiência que varia entre 0 e 1, ou seja, de $0 \%$ a 100\%, tanto no modelo BCC, como no modelo CCR. Os produtores que obtiveram índice de eficiência 
igual a 1 serão considerados efetivamente eficientes, ao identificar os melhores desempenhos em nível de operação cada produtor será comparado com os melhores desempenhos observados, esses chamados de benchmark (referência).

Vale destacar que foi utilizado o modelo CCR com orientação input, de forma a reduzir no processo de gestão da atividade os gastos com insumos correspondentes aos principais fatores de produção da atividade, mantendo constante o produto. Os resultados do DEA foram obtidos com a utilização do software DEAP 2.1 (Coelli, 1996).

$\mathrm{Na}$ identificação de quais variáveis discriminam a variação da eficiência, foi utilizado o modelo econométrico Tobit. Para determinação dos condicionantes da eficiência da pecuária leiteira, foi empregada como variável dependente (Y) os escores de eficiência, resultantes do modelo CCR. Já as variáveis explicativas $(X)$ foram determinadas com base no levantamento de dados da pesquisa, representadas por: assistência técnica, genética, custos, capacitação, tempo de atividade ( $n$ o anos de experiência), nível de instrução e complemento na alimentação.

Para encontrar os fatores explanatórios da eficiência, por meio do modelo de regressão Tobit, foi empregado o software Gretl (Cottrell \& Lucchetti, 2013).

Foram utilizados dados de fonte primária coletados junto aos produtores, referentes a 2016. Para isso utilizou-se questionários semiestruturados observando fatores no âmbito da produção e gestão, baseado em Paes-de-Souza (2007) e Rodrigues (2010), abstraindo as variáveis presentes no referido estudo.

\section{Resultados e discussão}

A partir dos dados obtidos com os produtores de leite, através das variáveis: $\times 1, \times 2, \times 3, x 4$ e y1, pode-se calcular a média, desvio padrão, mínimo e máximo, para caracterizar estatisticamente as DMU's estudadas, conforme Tabela 1.

Os resultados caracterizam as DMU's relacionando-as às variáveis correspondentes aos principais fatores de produção, sendo:

i) Mão de obra (homens):

As propriedades que fazem algum tipo de processamento do leite e posteriormente destinação (em geral comercializado ao consumidor final ou comércio como pizzarias, padarias e feiras), demandam maior número de mão de obra. Tal fato é observado em nove DMU's (60\%), estas distanciaram-se da média, dessas 6 processam o leite para algum derivado como: queijo, requeijão ou doce, e três o vendem in natura ao laticínio; tiram $\leq 100$ litros de leite ao dia, exceto duas unidades. Estão nesse grupo as DMU's 8, 5, 2 e 6 que apresentaram os piores resultados de eficiência na atividade. 
Por outro lado, as DMU's 9, 13 e 14 mostraram-se eficientes com a utilização de dois funcionários, destinando seu leite ao laticínio; encontram-se nessa mesma situação 40\% das DMU's, ordenhando $\geq$ 100 litros ao dia.

Tabela 1 - Estatística descritiva das variáveis de estudo

\begin{tabular}{lrrrrr}
\hline Variáveis & Unidade & Média & Desvio Padrão & Mínimo & Máximo \\
\hline Mão de obra (X1) & Homens & 2,13 & 0,92 & 1 & 4 \\
Hectares (X2) & Ha & 11,13 & 8,26 & 1 & 30 \\
Vacas em lactação (X3) & Cabeças & 18,07 & 14,65 & 3 & 54 \\
Investimento (X4) & $\mathrm{R} \$$ & $117.033,33$ & $130.642,43$ & $15.000,00$ & $400.000,00$ \\
Produção (Y1) & Litros & 8.888 & $10.828,92$ & 600 & 42.000 \\
\hline
\end{tabular}

Fonte: Dados da pesquisa.

Cabe considerar as diferenças na qualidade do capital humano, fator importante no desenvolvimento dos processos e tomada de decisão (Gomes, 2004). Sendo o nível de conhecimento/escolaridade do produtor apenas um item para mensurá-lo, observou-se entre os produtores $46,7 \%$ com ensino fundamental incompleto, 13,3\% com nível fundamental completo, $33,4 \%$ com ensino médio completo e 6,6\% com superior incompleto.

ii) Hectares (ha):

Estão relacionados a quantidade de vacas em lactação; composição de pastagem; tecnologia empregada e manejo (rotação de pastagem, irrigação, complementação alimentar, etc.), fatores esses que irão refletir na área necessária para manter os animais.

Somaram sete DMU's que apresentaram relação vaca/ha <1, ou seja, necessitam mais de um hectare para manter uma vaca, são propriedades que exibiram baixos níveis de eficiência. São oito as DMU's que apresentaram relação vaca/ha >1, variando entre 1,06 a 15 vacas/ha, reflexo do uso de complemento alimentar e tecnologia empregada sendo: rotação de pastagem (2,86 vacas/ha.), irrigação e rotação de pastagem (2,25 e 5,33 vacas/ha.), sistema de confinamento (4,37 vacas/ha.) e a massa de mandioca como principal fonte de alimento (15 vacas/ha.).

A área é composta em média por duas a três cultivares, principalmente do gênero Brachiaria as cultivares MG-4 (Brachiaria brizantha cv. MG-4), MG-5 (Brachiaria brizantha cv. MG-5 Vitória); do gênero Panicum a Mombaça (Panicum maximum) e Tanzânia (Panicum maximum). O uso de complementação alimentar foi observado em $100 \%$ das propriedades, sendo que $100 \%$ usam o sal mineral, 86,66\% também usam ração (concentrado), 46,66\% dispõe de silagem, e 33,33\% usam algum outro tipo de complemento (dos quais foram citados o melaço, a ureia, o bagaço do secador, o proteico de soja e a massa de mandioca).

Para Rodrigues (2010) e Gomes (2004), a não utilização de complemento alimentar, seja pela mineralização, volumosa ou concentrado, faz do produtor mais um extrator do que um profissional da 
atividade, além de que seu uso tem importância fundamental para o desempenho produtivo e reprodutivo, elementos que influenciam positivamente na eficiência dos produtores.

iii) Vacas em lactação ( $n$ o de animais):

As DMU's apresentaram uma média de 18,07 vacas, mínimo de 3, máximo de 54 e um desvio padrão de 14,65 vacas; essa variação se deve a fatores como: área disponível para a atividade, forma de manejo e tecnologia empregada. Os dados coletados no período final de inverno (setembro/outubro) trouxeram diferentes casos: i) muitas propriedades (60\%) tem seu rebanho de lactação reduzido, aumentando em $28 \%$ a 450\% (média de 174\%) o número de animais ordenhados no verão, caso que ocorre em unidades que a pastagem suporta poucos animais/ha. Assim, a complementação alimentar, como silagem, ração, dentre outros, deveria acontecer no manejo, mas o produtor apenas toma atitudes para que as vacas não decaiam durante esse período quando recebem sal, ração e em casos a silagem.

Por outro lado, algumas propriedades (26\%) conseguem manter o número de animais ordenhados no verão, reflexo de ações como: trabalhar de forma confinada; deter em seu rebanho vacas de raça leiteira (Gersey, Holandez, Gir); possuir novilhas e outras vacas para substituir as secas; irrigar a pastagem e rotacionar com piquetes, apontando assim melhor relação vaca/há, ações que refletem o manejo e uso de tecnologias corretas.

Por fim, existem as propriedades (14\%) que aumentam o rebanho em épocas do inverno, pois trabalham com IATF (inseminação artificial em tempo fixo), inseminação programada para a parição ocorrer até o início do inverno (de março a julho), época em que o leite se torna escasso para comercialização e consequentemente é valorizado, momento em que essas propriedades organizamse para operarem com o maior número de animais, que são mantidas com complementação alimentar como o sal, a ração (concentrado) e silagem. A pouca especialização genética do rebanho para produção de leite é para Gomes (2006) um dos principais problemas da pecuária leiteira, logo considerar a inseminação artificial como tecnologia para corrigir e melhorar o rebanho torna-se relevante.

iv) Investimento (R\$):

Os valores observados tem suas variações justificadas pela amplitude de investimentos de posse de cada propriedade, e que dependendo das funções que cada maquinário/equipamento atende, seu valor pode variar substancialmente, por exemplo: um resfriador com capacidade de 600 litros, investimento de $R \$ 10.000,00$, de 2.000 litros a $R \$ 25.000,00$, o mesmo ocorrendo com as benfeitorias, que em razão de suas dimensões, acabamento, dentre outros, terão variação de valor, refletindo na alta disparidade de investimento de uma propriedade para outra.

As DMU's que possuem ordenha e resfriador - dois itens de capital fixo que refletem o uso de tecnologia para essa atividade - representam $73,33 \%$, sendo que sete unidades ordenham duas vezes 
ao dia, e quadro ordenham uma vez ao dia; o restante da amostra ordenha manualmente, sendo que duas ordenham uma vez ao dia, e as outras duas unidades ordenham duas vezes ao dia. O número de ordenha é também um bom indicador da modernização dos sistemas e produção, o qual está relacionado à produtividade das vacas; a baixa produtividade em alguns casos justificam a ordenha realizada uma vez ao dia (Rodrigues, 2010). Para um investimento abaixo de $\mathrm{R} \$ 35.000,00$, nenhuma DMU possui ordenha mecanizada e/ou resfriador. Relatou-se que de modo geral as condições de manejo atendem as necessidades dos produtores, porém, havendo a possibilidade de fazer melhorias, $53 \%$ as realizariam.

Nota-se que pela dificuldade do produtor dispor de verba para investimentos na atividade, principalmente encontrados em propriedades pequenas e de baixa lotação, se torna complicado fazêlos de forma isolada, portanto uma alternativa para que possam usufruir de instrumentos com maior tecnologia, por exemplo resfriar o leite em um tanque resfriador, é integrar-se a uma cooperativa, associação ou sindicato voltado ao setor, pois esses geralmente dispõem de profissionais para atender seus membros, maquinário comunitário, e ainda interesses na negociação de insumo e produto a preços que favoreçam o produtor.

v) Produção (litros/mês):

Os valores da produção constituem reflexo das variáveis de entrada no processo de produção (mão de obra, hectares, vacas em lactação, investimento) anteriormente analisadas, quando se evidencia a diversidade das propriedades na composição e quantidade de seu rebanho, forma de manejo, ocupação de pastagem e investimento assumido. Os produtores considerados eficientes (níveis acima de 90\%), conseguiram uma média de produtividade de 21,26 litros/vaca/dia e os produtores ineficientes 12,55 litros/vaca/dia, uma variação de 40,96\%.

Diante dos dados, demonstram-se os seguintes resultados: i) as DMU's com eficiência abaixo de 50\%, tem uma produção diária por animal variando entre 5 e 12,5 litros; ii) as DMU's com 100\% de eficiência tem uma produção diária por animal entre 19,44 e 26 litros, dispondo ainda de pastagens indicadas para atividade leiteira por terem um alto grau de proteína, silagem e até massa de mandioca, além de usarem ração e sal, fatores que justificam a alta produção.

Com exceção das DMU's 9 e 5, as demais apresentaram uma média de produção acima de 10l/animal, e quando utilizado de complemento alimentar (silagem, sal e ração) passou para aproximadamente 15l/animal, demostrando a importância quando se pode disponibilizar ao animal esse complemento, explorando de forma saudável o potencial do rebanho.

Outro aspecto que coopera na organização, manutenção e promoção da atividade leiteira é o suporte através da assistência técnica, que em 20\% das DMU's não recebem em nenhum período do ano algum tipo de suporte (1, 5 e 8), apontadas com os menores índices de eficiência; de outra forma, 66,66\% recebem assistência pelo menos uma vez ao mês, por meio de entidades como o SENAR, AGRAER, associação ou técnico em particular, contribuindo para o manejo e melhor otimização dos 
fatores de produção, influenciando positivamente a eficiência. A Tabela 2 apresenta a distribuição das DMU's por classe de eficiência.

Tabela 2 - Distribuição das DMU's por classe de eficiência no modelo DEA-CCR (input)

\begin{tabular}{rrrrrrr}
\hline $\begin{array}{r}\text { Classe de } \\
\text { eficiência }\end{array}$ & $\%$ & $\begin{array}{r}\text { X1 (média) } \\
\text { homens }\end{array}$ & X2 (média) ha & X3 (média) vacas & X4 (média) R\$ & $\begin{array}{r}\text { Y1(média) } \\
\text { litros/mês }\end{array}$ \\
\hline $0,1-0,49$ & 26,67 & 1,50 & 7,50 & 5,50 & $107.125,00$ & 1.425 \\
$0,5-0,59$ & 6,67 & 3,00 & 20,50 & 8,00 & $15.000,00$ & 2.400 \\
$0,6-0,69$ & 13,33 & 3,50 & 13,50 & 18,50 & $187.500,00$ & 9.480 \\
$0,7-0,79$ & 13,33 & 2,50 & 15,75 & 20,00 & $47.500,00$ & 6.180 \\
$0,8-0,89$ & 6,67 & 2,00 & 7,00 & 20,00 & $45.000,00$ & 8.400 \\
$0,9-1,00$ & 33,33 & 1,80 & 10,20 & 26,80 & $159.400,00$ & 17.100 \\
\hline
\end{tabular}

Fonte: Autoria própria.

A classe de eficiência 0,9-1,00 identifica cinco produtores de leite correspondendo a 33,33\% da amostra (sendo $20 \%$ da amostra com eficiência de 100\%), dos quais foram eficientes com valores médios de investimento de $\mathrm{R} \$ 159.400,00$, vacas ordenhadas em 26,80, para uma área de 10,20 ha, com a utilização de 1,8 pessoas para manter a atividade.

As DMU's que estão nessa classe de eficiência são respectivamente: 9, 13 e 14 (Juti, Ponta Porã e Rio Brilhante) e 4 e 10 (Caarapó e Laguna Caarapã), sendo as três primeiras eficientes em 100\%. Esse desempenho pode ser justificado por alguns fatores, dentre os quais: i) presença de melhoramento genético, principalmente por inseminação artificial, com três casos de IATF inseminação artificial em tempo fixo (nas DMU's 100\% eficientes), buscando maior número de vacas em lactação nos períodos de inverno, rebanho com vacas de raça Gersey, Holandez, Gir; ii) controle de custos através da elaboração de planilhas, que em alguns casos são posteriormente passadas para o Excel'; iii) recebem assistência técnica ao mínimo uma vez ao mês; iv) dispõem de pastagem apropriada para o gado leiteiro, como Mombaça (Panicum maximum), Tifton 85 e também Brachiaria, além de complemento pela silagem e massa de mandioca; v) possuem pastagem irrigada (DMU 9) e/ou trabalha no modo confinado (DMU 10); vi) participam de curso com frequência, além de serem afiliados ao sindicato, cooperativa e alguns pertencentes à associação de produtores de leite, o que resulta na melhoria na comercialização da matéria-prima com o laticínio (melhores preços). Esses produtores consideram o momento atual da atividade leiteira razoável e/ou boa, possuem em média 46 anos de idade e 12 anos de atividade leiteira, dois completaram o ensino médio e três não completaram o ensino fundamental.

Observando o contraste de eficiência, temos as DMU's que apresentaram eficiência abaixo de $50 \%$ com seus insumos, representando a classe 0,1-0,49. A pior DMU foi a 8 (Itaporã), com apenas 19,3\% eficiência, seguida pela DMU 5 (Douradina), DMU 2 (Antônio João) e DMU 6 (Dourados) obtendo respectivamente uma eficiência de $26,6 \%, 45,3 \%$ e $48,2 \%$.

Essas DMU's possuem semelhanças, dentre as quais: i) apenas uma unidade comercializa o leite in natura para o laticínio; as demais fazem queijo e requeijão, destinando sua produção ao 
consumidor final (isso se deve a baixa produção, com média de 47,5 litros ao dia); ii) apenas as DMU's 2 e 6 recebem visitas técnicas pelo menos uma vez por mês; iii) as DMU's 8 e 6 buscam melhoramento genético através do touro inserido no plantel, as mesmas possuem ordenha mecânica e resfriador; iv) a pastagem que compõe a área destinada as vacas em lactação são indicadas para a atividade, sendo braquiária, mombaça e tifton, além dos animais receberem complemento alimentar.

Entretanto, a questão é se a área degradada e o complemento são suficientes para que os animais apresentem o devido retorno em produção; iv) esses produtores consideram o momento que estão vivendo na atividade leiteira ruim e/ou razoável, têm em média 60 anos de idade e 19 anos de atividade leiteira, $13 \%$ completaram o ensino médio, um completou o ensino fundamental e um não o completou; citaram o baixo incentivo que recebem para desenvolver a atividade e sentem-se desestimulados para trabalhar, além de não acreditarem que esse cenário possa melhorar, mas que mesmo assim mantém a esperança; do contrário parariam com a atividade.

Esses dois casos e os demais dados da Tabela 2, evidenciam que nem sempre a melhor produção média representa a melhor eficiência. Para Tupy e Yamaguchi (1998), a produtividade é medida através da relação entre os outputs (produtos) produzidos e os inputs (insumos) necessários para a produção, podendo variar devido as diferenças na tecnologia de produção, eficiência no processo de produção e no ambiente em que ocorre a produção.

O resultado que tem-se como exemplo é que DMU's que se enquadraram na classe de eficiência 0,9-1 fizeram investimentos médios abaixo das DMU's enquadradas na classe de eficiência $0,6-0,7$; isso vale também no uso médio de hectares destinados a vacas lactantes e mão de obra envolvida na atividade leiteira. Assim, vale reforçar o conceito de que a orientação escolhida reflete a opção por minimização de insumos (otimização dos fatores de produção).

De acordo com a Figura 1, visualiza-se a distribuição da eficiência técnica por DMU no modelo CCR-input. A média geral de eficiência entre as DMU's foi de 69,8\% de eficiência técnica, o que requer uma redução proporcional de 30,2\% para o conjunto de inputs estimados.

Comparando o resultado da eficiência global a outros trabalhos também voltados a atividade leiteira, usando o modelo CCR - input, Tupy e Yamaguchi (2002) obtiveram uma eficiência técnica média de $73,3 \%$, indicando que os produtores podem, em média, reduzir em até $29,7 \%$ dos seus gastos com insumos sem comprometer a renda obtida com a venda de leite.

$\mathrm{Na}$ análise de benchmarks, as DMU's 9, 13 e 14 são pares de excelência para as demais unidades classificadas como ineficientes, que obtiveram eficiência inferior a um. Para uma firma eficiente, todos os valores de $\lambda$ serão zero; para uma firma ineficiente, os valores de $\lambda$ serão os pesos utilizados na combinação linear de outras firmas eficientes, que influenciam a projeção da firma ineficiente sobre a fronteira calculada. Isso significa que, para uma unidade ineficiente, existe pelo menos uma unidade eficiente, cujos pesos calculados fornecerão a firma virtual ineficiente, mediante a combinação virtual (Tupy \& Yamaguchi, 1998). 
Figura 1 - Distribuição da eficiência técnica (\%) por DMU no modelo DEA CCR (input)

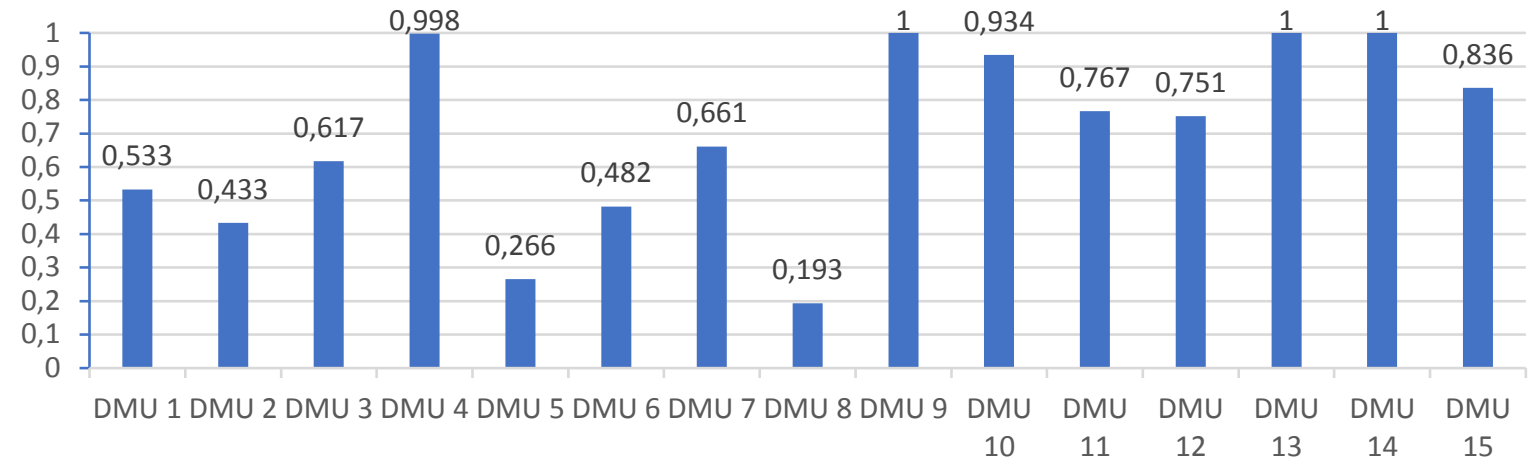

Fonte: Autoria própria.

As DMU's que alcançaram o máximo de eficiência são consideradas "pareto eficientes", pois já otimizaram a produção ao máximo utilizando os insumos que qualquer redução na quantidade dos inputs reduziria os outputs. Portanto, são propriedades que já encontraram um equilíbrio na atividade leiteira, na relação produto/insumo, comparando-se ao grupo amostral analisado. Para melhor visualização segue o ranking da eficiência no modelo CCR (Tabela 3).

Tabela 3 - Ranking de eficiência modelo CCR

\begin{tabular}{lcc||lcc}
\hline Município & DMU & Eficiência & Município & DMU & Eficiência \\
\hline Juti & 9 & 1 & Fátima do Sul & 7 & 0,661 \\
Ponta Porã & 13 & 1 & Aral Moreira & 3 & 0,617 \\
Rio Brilhante & 14 & 1 & Amambai & 1 & 0,533 \\
Caarapó & 4 & 0,998 & Dourados & 6 & 0,482 \\
Laguna Caarapã & 10 & 0,934 & Antônio João & 2 & 0,433 \\
Vicentina & 15 & 0,836 & Douradina & 5 & 0,266 \\
Maracaju & 11 & 0,767 & Itaporã & 8 & 0,193 \\
Nova Alvorada do Sul & 12 & 0,751 & & & \\
\hline
\end{tabular}

Fonte: Autoria própria.

Correlacionando o ranking de eficiência e a variável № vacas em lactação, municípios como Dourados e Itaporã possuem o mesmo no de vacas que Maracaju, que obteve a melhor posição em eficiência técnica; portanto esses municípios, pela quantidade de vacas em lactação, e observando outros fatores de produção, diminuindo os desperdícios juntamente com melhorias no manejo, são capazes de se tornarem eficientes tecnicamente.

Os resultados da Tabela 4 resumem os indicadores para as diferenças entre os dados atuais e os alvos (target) a serem atingidos para a DMU 8, que obteve o pior índice de eficiência observado, inclusive as folgas (slacks) que representam os desperdícios de insumos, ou seja, quanto maior o seu valor, maior o desperdício, inferindo no alto descarte de insumos.

Tabela 4 - Alteração dos valores atuais das variáveis da DMU ineficiente, para tornar-se eficiente 


\begin{tabular}{cccccc}
\hline DMU & Variáveis (Inputs) & Valor Atual (R\$) & Folgas (R\$) & Alvo (R\$) & $\Delta \%$ \\
\hline \multirow{3}{*}{$8(0,193)$} & Pessoas $\left(\mathrm{n}^{\circ}\right)$ & 1 & - & 1 & - \\
& Área (ha) & 10 & 6,111 & 3,889 & $-61,1$ \\
& Vacas ( $\left.\mathrm{n}^{\circ}\right)$ & 8 & 4,667 & 3,333 & $-58,3$ \\
& Investimentos (R\$) & $93.500,00$ & 76092,59 & $17.407,41$ & $-81,38$ \\
\hline
\end{tabular}

Fonte: Autoria própria.

As folgas referem-se às quantidades extras a serem reduzidas nos insumos para que o produtor atinja o conjunto eficiência radial (Eficiência Radial=alvo+folgas), após todos os insumos terem sido minimizados de maneira proporcional (Surco, 2004). Os alvos seriam o valor de referência mínimo até o qual o produtor poderia reduzir os valores atuais correspondentes às variáveis; facilitando o gestor quanto ao processo de tomada de decisão e a forma com que irá se organizar para adequar os insumos e alcançar os objetivos.

A partir dessas observações gerais, os principais inputs que apresentaram folgas a serem ajustadas para o alcance de maior eficiência foram: i) investimento, sendo que as DMU's 5, 6, 7, 8, 10 e 15 devem diminuir em média 43,5\% do valor investido; ii) vacas em lactação, sendo que as DMU's 8 , 10, 12 e 15 devem ajustar suas folgas em média de 38,75\%; iii) hectares, as DMU's 5, 8 e 12 devem ajustar sua área destinada as vacas em lactação em média de 52\%.

A DMU 8 demanda um maior ajuste dos fatores, devendo ajustar suas folgas reveladas em hectares, vacas em lactação e investimento, devendo diminuir tais inputs em 61\%, 58\% e 81\%, evidenciando o mal aproveitamento dos insumos que ocorre na propriedade, refletindo posteriormente em baixo rendimento. Com relação aos alvos, para torná-la eficiente em 100\%, deveria reduzir: a área de 10 ha para 3,88 ha; o número de vacas de 8 para 3,3 (aproximadamente 3 animais) e investimentos de $R \$ 93.500,00$ para $R \$ 17.407,40$. A mesma lógica serve para as demais DMU's, através de relatórios individuais para cada DMU.

Desta forma, considerando um conjunto de alternativas operacionais na produção leiteira, algumas estratégias podem ser adotadas nas unidades, dentre elas, o melhor aproveitamento da infraestrutura condizente aos investimentos das propriedades em questão.

Com relação ao modelo BCC (ou VRS - variable returns to scale), desenvolvido por Banker, Charnes e Cooper (1984), para análise de variável de escala, a grande maioria das DMU's apresentam ineficiência de escala. Assim, a Tabela 5 mostra os tipos de retornos de escala contidos nas unidades analisadas, indicando uma predominância de retornos crescentes de escala, de forma que dado o conjunto de insumos, podem melhor expandir a produção obtida, limitada em 600 litros/mês, para uma média de 8.888 litros/mês entre essas unidades, tornando-se factível a racionalização dos insumos no ciclo produtivo.

Pode-se observar também que $20 \%$ dos produtores apresentaram escore de eficiência igual à unidade no modelo com retornos constantes de escala, ou seja, empregaram de maneira racional os insumos e a escala de produção adequada, servindo como referência para as demais unidades (DMU's 9,13 e 14). 
Tabela 5 - Retornos de escala correspondentes às unidades em análise

\begin{tabular}{lll||lll}
\hline DMU & Retornos de escala & CCR & DMU & Retornos de escala & CCR \\
\hline 1 & Crescente & 0,533 & 9 & Constante & 1,000 \\
2 & Crescente & 0,433 & 10 & Crescente & 0,934 \\
3 & Crescente & 0,617 & 11 & Crescente & 0,767 \\
4 & Crescente & 0,998 & 12 & Crescente & 0,751 \\
5 & Crescente & 0,266 & 13 & Constante & 1,000 \\
6 & Crescente & 0,482 & 14 & Constante & 1,000 \\
7 & Crescente & 0,661 & 15 & Crescente & 0,836 \\
8 & Crescente & 0,193 & & & \\
\hline
\end{tabular}

Fonte: Autoria própria.

Com o intuito de testar estatisticamente as relações de causalidade e os efeitos de algumas variáveis que podem influenciar a eficiência dos produtores de leite, foi realizada a estimação do modelo Tobit (Fethi, Jackson \& Weyman, 2000), conforme Tabela 6.

Tabela 6 - Resultados do modelo Tobit

\begin{tabular}{lrrrl}
\hline & Coeficiente & Erro Padrão & p-valor & \\
\hline Assist. Técnica & 0.262116 & 0.122264 & 0.03204 & $* *$ \\
Genética & 0.315558 & 0.0527385 & $<0.00001$ & $* * *$ \\
Custos & -0.0535071 & 0.0541216 & 0.32284 & $\mathrm{~ns}$ \\
Capacitação & 0.0691024 & 0.0480333 & 0.15025 & $\mathrm{~ns}$ \\
Experiência & -0.00294131 & 0.00383752 & 0.44340 & $\mathrm{~ns}$ \\
Nível Instrução & -0.073215 & 0.0477164 & 0.12494 & $\mathrm{~ns}$ \\
Compl. Alimentar & 0.142969 & 0.0564115 & 0.01126 & $* *$ \\
\hline
\end{tabular}

Nota: ** significância a 5\%; *** significância a 10\%; ns não significante.

Fonte: Autoria própria.

Das variáveis consideradas no modelo, quatro não se mostraram estatisticamente significantes, não sendo, portanto, fatores importantes para explicar a eficiência dos produtores de leite da microrregião de Dourados. Mostraram-se significantes as variáveis: assistência técnica, genética e complementação alimentar, conforme informações obtidas com os produtores.

A variável genética mostrou-se significante a $10 \%$ e com o sinal esperado. Sendo assim, o potencial genético do rebanho influencia positivamente a eficiência dos produtores, sendo um fator relevante na eficiência, visto que esta poderia ser aumentada caso se estivesse produzindo com maior investimento na qualidade do animal, adaptável às condições ambientais da região.

Ao observar o uso de inseminação artificial apenas seis DMU's fazem uso, nove não utilizam (DMU's 5, 6, 7, 8,11, 12, no entanto buscam melhorar a genética do rebanho através do touro). Duas alternativas são principais para busca do melhoramento genético: i) inseminação artificial, sendo mais barata, porém é um método mais lento, cerca de sete a 10 anos, para mudar efetivamente o perfil do rebanho, ii) utilização de embriões, método muito mais caro que o anterior, requerendo um grau de sofisticação técnica que a maioria dos produtores não possui, porém a mudança do perfil do rebanho ocorre em torno de três a quatro anos. Apesar da inseminação ser mais acessível, poucos produtores a utilizam (Lima e Pereira, 1995). 
Já as variáveis assistência técnica e complementação alimentar mostraram-se significantes ao nível de 5\% e apresentaram sinal esperado, revelando que melhores acompanhamentos das atividades produtivas reforçam melhoria no manejo nutricional, corroborando positivamente para o nível de eficiência, sobretudo ao controle de custos, representado em sua totalidade pelas unidades eficientes. Convém destacar que 53\% das unidades possuem ao mínimo ensino fundamental completo, porém sem o devido conhecimento dos coeficientes técnicos de produção, o que limita a atividade econômica, pressupondo a redução do nível de eficiência relacionado a otimização dos fatores produtivos.

Para a variável assistência técnica, três DMU's não possuem acompanhamento, sendo Amambai, Douradina e Itaporã; as demais recebem assistência no mínimo uma vez ao mês, com exceção de Aral e Maracaju que recebem assistência, porém não mensalmente. O extensionista tem suma importância na ligação entre o setor de pesquisa e agricultor, sendo que sua falta se relaciona com o surgimento de problemas na propriedade, como alimentação do rebanho deficitária, necessidade de investimentos em instalações, melhoria do plantel, dentre outros, que facilmente poderiam ser resolvidos caso houvesse orientação (Lima \& Pereira, 1995).

Para a variável complementação alimentar, observou-se que 100\% das DMU's utilizam complemento nutricional, principalmente o sal mineral e a ração. O produtor tem consciência da importância dessa variável para manter a saúde animal e ainda aumentar a produção. Esse é o item mais importante de todos e o de melhor solução, procedendo a uma alimentação adequada em quantidade, qualidade e barata, utilizando ao máximo os recursos do produtor, de forma a evitar seus efeitos negativos, tais como: aumento do intervalo entre partos, redução do período de lactação e diminuição do volume de leite produzido por vaca (Lima \& Pereira, 1995).

\section{Considerações finais}

As unidades produtoras de leite (DMU's) com maior eficiência apresentaram características semelhantes em relação aos seus inputs e outputs, dentre elas o investimento (valores mais expressivos investidos em maquinário, benfeitorias e equipamentos) e produção (maior volume produzido > 100 I ao dia, resultante do número de animais em lactação, melhoramento genético e alimento disponível).

Por outro lado, as DMU's com menor eficiência também apresentaram características semelhantes em relação aos seus inputs e outputs, dentre elas o tamanho da área (possuem em geral menor aproveitamento na relação vaca/ha $=<1$; apesar de terem pastagem apropriada, não utilizam o sistema rotacionado nem de irrigação, além do que as áreas possam estar degradadas) e produção (menor quantidade produzida, com valores $<100$ I ao dia).

Ainda assim, no processo de identificação das variáveis que podiam afetar a eficiência dos produtores de leite, observou-se que as que influenciaram positivamente foram: assistência técnica, 
genética, capacitação e complementação alimentar. Já as variáveis que influenciam negativamente, embora não significativas, mas com relação direta com a variável assistência técnica, foram: custos, experiência e nível de escolaridade.

Nesse sentindo, para que mudanças efetivamente ocorram no setor, é preciso que os produtores busquem trabalhar com seus insumos de forma racionalizada, além de não se isolarem na propriedade. Ainda assim, torna-se necessário que o produtor demande por suporte técnico, mão de obra especializada presente no seu cotidiano - a ausência desse fator está diretamente ligada ao desempenho de outros fatores, além de ser proativo na busca de especialização em sua atividade.

Portanto, espera-se que a atividade leiteira faça parte de um processo que se caracterize por desenvolver não somente aspectos quantitativos, mas principalmente aspectos qualitativos, gerando frutos que contemplem o aumento de oferta de emprego, possibilidade de capacitação, maior distribuição de renda e produtividade, favorecendo a permanência no campo com melhores condições de vida.

\section{Referências}

Alves, E. (1999). Medidas de eficiência: métodos não paramétricos. Brasília, DF: EMBRAPA, p. 28.

Ali, A. A. \& Seiford, L.M. (1993). The mathematical approach to efficiency analysis. In: Fried, H., Lovell, C.A.K. \& Schmidt, S. (Eds.). The measurement of productive efficiency: techniques and applications. Oxford: Oxford University, p. 120-159.

Anuário do Leite. (2019). Indicadores da produção mundial de leite. Embrapa, 53 p.

Banker, R. D.; Charnes, A. \& Cooper, W. (1984). Some Models for Estimating Technical and Scale Inefficiencies, in Data Envelopment Analysis. Management Science, 30(9), 1078-1092.

Barbosa, F. R. G. M. (2013). Índice de desenvolvimento dos municípios da microrregião de DouradosMS: uma aplicação da análise fatorial. 103f. UFGD - Programa de Pós-Graduação em Agronegócios Dourados.

BNDES. (2013). Banco Nacional de Desenvolvimento. BNDES Setorial, n. 37, p. 371- 398.

Brasil. (2015). Mato Grosso do Sul. Secretaria de Estado de Meio Ambiente e Desenvolvimento Econômico - SEMADE. Perfil Estatístico de Mato Grosso do Sul. Ano base: 2014 Campo Grande: p. $111 \mathrm{p}$.

Campos, K. C. \& Piacenti, C. A. (2007). Agronegócio do leite: cenário atual e perspectivas. In: SOBER. XLV CONGRESSO DA SOBER - Londrina/PR. Disponível em: <http://www.sober.org.br/palestra/6/1152.pdf>. Acesso em: 10 Jan. 2018.

Carmo, H. M. O. (2012). Análise envoltória de dados para avaliação da eficiência da avicultura familiar em Alagoas / Hérmani Magalhães Olivense do Carmo. 105 f.: il.

Charnes, A., Cooper, W.W. \& Rhodes, E. (1978) Measuring the efficiency of decision making units. European Journal of Operational Research, 2(6), 429-444. 
Coelli, T. (1996). A guide to FRONTIER Version 4.1: a computer program for stochastic frontier production and cost function estimation. Centre for Efficiency and Productivity Analysis. University of New England.

Cottrell, A \& Luchetti, R. (2013). Gretl User's Guide. Disponível em: <http://ricardo.ecn.wfu.edu/pub//gretl/manual/en/gretl-guide.pdf>. Acesso em: 16 Jan. 2017.

Fethi, M. D.; Jackson, P. M. \& Weyman-Jones, T. G. (2000). Measuring the Efficiency of European Airlines: An Application of DEA and Tobit Analysis. In: Annual Meeting of the European Public Choice Society, Siena, Italy, $32 \mathrm{p}$.

Fiore, E. G. \& Araújo, P. F. C. (2002). Relações econômicas entre educação e produto social da agricultura. Estudos Econômicos, São Paulo, 32(4), 643-663.

Gomes, A. L. (2006). Indicadores de eficiência e economias de escala na produção de leite: um estudo de caso para produtores dos estados Rondônia, Tocantins e Rio de Janeiro. 97f. Tese (Doutorado em Ciências) - Universidade de São Paulo, São Paulo.

Gomes, A. T. \& Leite, J. L. B. (2001). O relacionamento na cadeia agroindustrial do leite para os novos tempos. In: Gomes, A. T.; Leite, J. L. B. \& Carneiro, A. V. O agronegócio do leite no Brasil - Juiz de Fora. EMBRAPA Gado de Corte.

Gomes, E. G. \& Mangabeira, J. A. C. (2004). Uso de análise de envoltória de dados em agricultura: o caso de Holambra. Entrevista, 6(1), 19-27.

Kassai, S. (2002). Utilização de análise envoltória de dados (DEA) na análise de demonstrações contábeis. Tese. (Doutorado). 318f. Universidade de São Paulo, Faculdade de Economia, Administração e Contabilidade, São Paulo.

Lima. J. F. \& Pereira, A. P. G. (1995). A Cadeia Agroindustrial do Leite e seus Derivados. p. 110-134.

Lins, M. P. E. \& Meza, L. A. (2000). Análise envoltória de dados e perspectiva de integração no ambiente de apoio à decisão. Ed: COPPE/UFRJ. Rio de Janeiro.

Matos, L. L. (1996). Perspectivas em alimentação e manejo de vacas em lactação. Embrapa - Centro Nacional de Pesquisa de Gado de Leite. Juiz de Fora: Embrapa Gado de Leite.

Mondaini, I. (1996). A rentabilidade da atividade leiteira: um caso de produtores no médio Paraíba do Estado do Rio de Janeiro. Lavras: UFLA, 83f., Dissertação de Mestrado em Administração Rural.

Paes-de-Souza, M. (2007). Governança no Agronegócio: Enfoque na Cadeia Produtiva do Leite. 1. ed. Porto Velho: Edufro, v. 200. 180 p.

Pitombo, L. H. (2016). Leite. Anuário DBO 2016. São Paulo, 34(423), 82-94.

Rodrigues, M. H. S. (2010). Avaliação de eficiência de produtores de leite utilizando análise envoltória de dados: o caso do município de Rolim de Moura no Estado de Rondônia. Dissertação (Mestrado em Administração). 120f. NUCS - Programa de Pós-Graduação em Administração, Universidade Federal de Rondônia. Porto Velho, Rondônia.

Santos, J. A.; Vieira, W. C. \& Baptista, A. J. M. S. (2005). Eficiência Técnica em Propriedades Leiteiras da Microrregião de Viçosa - MG: Uma Análise Não Paramétrica. Organizações Rurais e Agroindustriais, Lavras, 7(2), 162-172. 
Sban. (2015). Sociedade Brasileira de Alimentação e Nutrição. A Importância do Consumo de Leite do Atual Cenário Nutricional Brasileiro 2015. Documentos técnicos.

Surco, D. F. (2004). Desenvolvimento de uma ferramenta computacional para avaliação de eficiência técnica baseada em DEA. 129f. Dissertação (Mestrado em Métodos numéricos em engenharia). UFPR. Curitiba.

Tupy, O. \& Yamaguchi, L. C. T. (1998). Eficiência e Produtiva: conceitos e medição. Agricultura em São Paulo, SP, 45(2), 39-51.

Tupy, O. \& Yamaguchi, L. C. T. (2002). Identificando Benchmarks na Produção de Leite. SOBER Sociedade Brasileira de Economia e Sociologia Rural. Revista de Economia e Sociologia Rural, 40(1), 81-96.

Zoccal, R. (2012). Quantos são os produtores de leite no Brasil? Panorama do leite, Juiz de Fora, n. 64.

Recebido em: 21 fev. 2019 / Aprovado em: 15 ago. 2019

Para referenciar este texto

American Psychological Association (APA)

Buss, R. E., Sabbag. O. J., \& Mendieta, F. H. P. (2020). Eficiência da produção leiteira na microrregião de Dourados/MS: aplicação da análise envoltória de dados. Exacta, 18(3), 649-667. https://doi.org/10.5585/ExactaEP.v18n3.12360. 